\title{
Product, process and industrial system: innovative research tracks
}

\author{
Jean-François Petiot • Benoit Furet
}

Published online: 11 November 2010

(C) Springer-Verlag 2010

This issue of IJIDeM journal is devoted to innovative approaches for the optimization of products, processes or industrial systems. The mentioned topics are the mirror of research activities emerging from AIP PRIMECA network, involved in the realization of our journal. We propose in this short paper to introduce the cutting-edge research in respective fields of specialization of Product Design and to give an overview of some recent hot research topics in industrial engineering.

\section{Introduction}

Nowadays, market globalization has a deep impact on methods of work and organization of enterprises. The rapid development of innovative products with controlled environmental impacts is a key challenge for companies. There is therefore a clear industrial need for short development cycles, reliable prediction of the risks and the costs of a project, and mastering and control of the quality. After a focus on the integration of manufacturing constraints into the design process in the 1990s, we notice now an opening of the design sciences to disciplines such that human factors, marketing, cognitive ergonomics, knowledge modeling, artificial intelligence, etc. New disciplines, such a systems engineering, mechatronics,

\footnotetext{
J.-F. Petiot $(\varangle)$

UMR CNRS 6597, Ecole Centrale de Nantes, IRCCyN, 1, rue de la Noë, BP92101, 44321 Nantes Cedex 3, France e-mail: jean-francois.petiot@irccyn.ec-nantes.fr

B. Furet

UMR CNRS 6597, Université de Nantes, IRCCyN, 1, rue de la Noë, BP92101, 44321 Nantes Cedex 3, France e-mail: Benoit.Furet@irccyn.ec-nantes.fr
}

sustainable design, smart machining, robot machining,... emerge now in the field of engineering sciences and constitute progressively their corpus of knowledge, based on the work of researchers. For the sake of clarity, we propose to distinguish three main complementary items to describe the research in engineering science:

- Product

- Process

- Industrial system

As an introduction to this issue of IJIDeM journal, this paper will highlight some emerging research topics according to this classification.

\section{Product}

The research dealing with product design starts with the statement of user needs, and more generally the integration in the design process of the interaction between users/customers and products.

\subsection{Customer oriented design}

The trend is now to provide a rich, valuable and pleasant experience to the user, during the use of a product. In this context, we notice now tight connections between engineering design, marketing and industrial design. Human factors considerations are increasingly being incorporated into the product design process: User centered design [1], kansei engineering [2], preference modeling [3], sensory analysis are for example important themes in the current research in design science. 


\subsection{Product modeling and simulation}

The development of reliable engineering models is a second important track in order to get reliable simulations of the behavior of the product [4]. These simulation are mainly based on the digital mock-up and on virtual reality tools, which are increasingly introduced in the design process. Virtual reality (VR) seems to offer promising functionalities for the assessment on virtual products [5]. The Virtual reality interfaces available on the market are now mature enough for suggesting to the user relevant feelings and sensations. These interfaces and processing modules can be used to simulate the sensory immersion of the user and his/her interactions with a virtual product. The main issue is now to learn how to use these interfaces and to define relevant methods for their integration into the design process.

\subsection{Optimization}

Another relevant track concerns the "optimal design" paradigm [6], and exploration of design spaces: decision-making models are used to describe design alternatives, and mathematical methods are developed for the search in the design space of "optimal" designs. In this context, "interactive" optimization, with the introduction of the designer or the user in the design loop, is a promising approach [7].

\section{Process}

The second item subjected to research actions concerns the industrial processes set up in a company. These industrial processes can concern manufacturing processes, or organizational processes of the enterprise.

\subsection{Manufacturing process}

In civil aircraft, composite materials now account for as much as $50 \%$ of the structural mass, and the proportion is expected to keep on increasing. All of the basic composite parts are obtained using different manufacturing processes, such as hand lay-up or automatic lay-up followed by autoclave cure, resin transfer molding (RTM), or resin infusion. They also require milling to obtain functional surfaces of sufficiently high quality, and drilling to obtain the bore diameters needed for mechanical assembly.

High speed machining (HSM) allows higher productivity and better product quality. However, if problems occur, the significant speeds may cause serious damages to the workpiece and even to the machine tool. Tool condition monitoring (TCM) systems and smart machining methods and systems (SMMS) could be efficient solutions to improve productivity and quality.
Serial robots are mainly used in industry to realize tasks requiring a good repeatability, but not necessarily a good global pose accuracy of the robot end-effector. Nevertheless, they start to be used to realize machining operations such as trimming, deflashing, degating and sawing of composites parts that require high precision and stiffness. Therefore, robots need good kinematic and elastostatic performance to realize such operations. It is then relevant to pay attention to the robots performance in order to optimize their use for machining operations. Future research works will deal with the elastodynamic model and performance of the robot in order to predict its behaviour during high speed machining operations. Moreover, the dynamic parameters of the robot will be identified in addition to geometric and stiffness parameters.

\subsection{Design process and collaborative design}

Beyond the classical design theories of the state of the art (value analysis, axiomatic design, systematic design, robust design, ...), a number of research are dealing with the product development process, and the tools supporting it. Multisite organizations are now a current practice in the context of extended enterprise. On the other hand, concurrent engineering approach needs integration of all activities and decisions during the whole life cycle of the product. Nowadays, all actors of the extended enterprise working on a given product have to collaborate and share data related to the design and the development of the product (PLM, information system). They have to bring their know-how and competencies during the design process regardless of communication, language and cultural problems. In this context, enterprises and research laboratories are now looking for new tools and methods to collaborate and work together [8].

\section{Industrial system}

Finally, the research on industrial systems widens the scope of the studies on the entire enterprise and the industrial organization. This topic leads to the emergence of a discipline, the industrial engineering, which build progressively its corpus of knowledge.

\subsection{Reverse engineering}

With the development of computer-aided design (CAD), reverse engineering has become an interesting method to create a 3D virtual model of an existing physical part [9]. The reverse-engineering process involves measuring an object and then reconstructing it as a 3D model. The physical object can be measured using 3D scanning technologies, laser scanners, structured light digitizers or computed tomography. 
The challenge in reverse engineering is to extract knowledge about the geometry of the parts in order to built relevant geometrical models.

\subsection{Model based design}

This emergent approach is applied in designing embedded software, in order to improve productivity. It provides an efficient method for defining a communication framework throughout the design process for simulations during the development cycle ("V" diagram).

\section{References}

1. Jordan, P.: Designing Pleasurable Products: An Introduction to the New Human Factors. Taylor \& Francis, London (2002)
2. Nagamachi, M.: Kansei engineering: a new ergonomic consumeroriented technology for product development. Int. J. Industr. Ergon. 15, 3-11 (1995)

3. Green, P., Carroll, J., Goldberg, S.: A general approach to product design optimization via conjoint analysis. J. Market. 43, 17 (1981)

4. Lewis, K., Chen, W., Schmidt, L. (eds.): Decision Making in Engineering Design. ASME Press, New York (2006)

5. Moreau, G., Fuchs, P., Stergiopoulos, P.: Applications of Virtual Reality in the manufacturing industry: from design review to ergonomic studies. Revue "Mécanique Et Industries" 5(2), 171179 (2004)

6. Papalambros, P.Y., Wilde, D.J.: Principles of Optimal Design, 2nd edition. Cambridge University Press, New York (2000)

7. Yannou, B., Dihlmann, M., Awedikian, R.: Evolutive design of car silhouettes. DETC2008-49439. In: Proceedings of IDETC/CIE 2008, August 2008, Brooklyn, NY, USA

8. Schmidt, K.: Cooperative design: prospect for CSCW in design. Des. Sci. Technol. 6(2), 5-18 (1998)

9. Varady, T., Martin, R.R., Cox, J.: Reverse engineering of geometric models - an introduction. Comput Aid Des. 29(4), 255-268 (1997) 